\title{
Breast Milk Fatty Acids, Eicosanoids, and Cytokines in Mothers with and without Allergic Disease
}

\author{
KIRSI LAIHO, ANNA-MAIJA LAMPI, MARI HÄMÄLÄINEN, EEVA MOILANEN, \\ VIENO PIIRONEN, TAINA ARVOLA, STINA SYRJÄNEN, AND ERIKA ISOLAURI \\ Department of Paediatrics [K.L., E.I.] and Institute of Dentistry [S.S.], University of Turku, Turku; \\ Department of Applied Chemistry and Microbiology, University of Helsinki, Helsinki [A.-M.L., V.P.]; The \\ Immunopharmacological Research Group, Medical School [M.H., E.M.] and Department of Pediatrics \\ [T.A.], University of Tampere and Tampere University Hospital, Tampere, Finland
}

\begin{tabular}{|c|c|}
\hline \multicolumn{2}{|c|}{ ABSTRACT } \\
\hline $\begin{array}{l}\text { Allergic disease (AD), including atopic eczema, asthma, al- } \\
\text { lergic rhinitis, and food allergy, is characterized by an imbalance } \\
\text { between cytokines produced by distinct T-helper cell subtypes. } \\
\text { Whether this imbalance can be transferred from mother to breast } \\
\text { milk remains to be established. The objective was to investigate } \\
\text { the concentrations and interactions of nutritional and inflamma- } \\
\text { tory factors in breast milk. Breast milk samples were collected } \\
\text { from mothers with AD }(n=43) \text { and without AD }(n=51) \text {. The } \\
\text { concentrations of transforming growth factor (TGF)- } \beta_{2} \text {, tumor } \\
\text { necrosis factor- } \alpha \text {, IL-4, IL-10, prostaglandin } \mathrm{E}_{2} \text {, and cysteinyl } \\
\text { leukotrienes were measured by immunoassays and fatty acid } \\
\text { composition by gas chromatography. Mothers with AD had a } \\
\text { lower concentration of TGF- } \beta_{2} \text { in breast milk [median (inter- } \\
\text { quartile range), } 420 \text { ( } 278-701) \text { ng/L] compared with those with- } \\
\text { out AD [539 ( } 378-1108) \text { ng/L; } p=0.003 \text {, whereas other } \\
\text { cytokines, prostaglandin } \mathrm{E}_{2}, \text { and cysteinyl leukotriene concen- } \\
\text { trations or fatty acid composition were not significantly different } \\
\text { between the groups. The breast milk inflammatory factors and } \\
\text { fatty acid composition were shown to be related. A positive } \\
\text { association was observed between TGF- } \beta_{2} \text { and the proportion of }\end{array}$ & $\begin{array}{l}\text { polyunsaturated fatty acids }(p=0.038) \text { and a negative associa- } \\
\text { tion between TGF- } \beta_{2} \text { and the proportion of saturated fatty acids } \\
(p=0.029) \text { in breast milk. The reduced TGF- } \beta_{2} \text { concentration in } \\
\text { the breast milk of mothers with AD may interfere with the } \\
\text { development of the mucosal immune system of the breast-fed } \\
\text { infant. The observed associations between nutritional and inflam- } \\
\text { matory factors in breast milk suggest that it may be possible to } \\
\text { influence the immunologic properties of breast milk by dietary } \\
\text { intervention of the mother. (Pediatr Res 53: 642-647, 2003) } \\
\text { AD, allergic disease } \\
\text { TGF- } \boldsymbol{\beta}_{2} \text {, transforming growth factor } \beta_{2} \\
\text { TNF- } \alpha \text {, tumor necrosis factor } \alpha \\
\text { PGE }, \text { prostaglandin E } \\
\text { Cys-LT, cysteinyl leukotrienes } \\
\text { PUFA, polyunsaturated fatty acids } \\
\text { SFA, saturated fatty acids } \\
\text { TH, T-helper cell } \\
\text { Tr, T-regulatory cell }\end{array}$ \\
\hline
\end{tabular}

Breast milk provides the infant with nutrients for growth and development and immune protection to compensate for the immature and inexperienced defense mechanisms at mucosal surfaces. Although the evidence is inconclusive, breast-feeding during the first months after birth seems to protect the infant against $\mathrm{AD}$, including atopic eczema (1), allergic rhinitis (2), asthma (3), and food allergy (4). However, it has been documented that parental and particularly maternal AD increases the risk of $\mathrm{AD}$ in the infant $(5-8)$. The intensive relationship

Received August 9, 2002; accepted October 21, 2002.

Correspondence: Kirsi Laiho, Ph.D., Department of Pediatrics, University of Turku, P.O. Box 52, 20521 Turku, Finland; e-mail kirsi.laiho@utu.fi

Supported by the Academy of Finland, Ministry of Social Affairs and Health of Finland, Juho Vainio Foundation, and Medical Research Fund, Tampere University Hospital.

DOI: 10.1203/01.PDR.0000055778.58807.C8 between the mother and the infant during pregnancy and breast-feeding may result in modulation of the immune system of the infant to favor the development of allergic immune responder phenotype. As allergic inflammation is typically characterized by altered production of mediators such as cytokines and immunoglobulins $(9,10)$, it is possible that the AD of the mother influences the breast milk composition. Such variation in composition may in turn affect the maturation of the defense mechanisms of the gastrointestinal tract and thus the health status of the breast-fed infant.

Cytokines, fatty acids, and eicosanoids - depending on the mediator type - have the capacity to exert both proinflammatory and antiinflammatory effects (11-13), but little is known as to their concentrations and associations within breast milk. In addition, whether the $\mathrm{AD}$ of the mother is reflected in the 
composition of her breast milk has not been ascertained. The objectives of the present study were to investigate 1) the concentrations and interactions of the nutritional and inflammatory factors within breast milk and 2) the composition of breast milk in mothers with $\mathrm{AD}$ compared with that of mothers without.

\section{METHODS}

Subjects and study design. The study population comprised 43 mothers with and 51 mothers without AD. Breast-feeding mothers from families participating in other, allergic unrelated studies at Turku and Tampere University Hospitals were asked to donate breast milk samples to the study. Mothers with chronic diseases other than $\mathrm{AD}$ were excluded. $\mathrm{AD}$ in the mothers was classified as atopic eczema, asthma, allergic rhinitis, or food allergy according to the mothers' own reports of doctor-diagnosed $\mathrm{AD}$ or previous use of medication for symptoms of $\mathrm{AD}$. At the time of breast milk sample collection the infants were on average 2.3 mo old. Fifty-nine of the infants were exclusively breast-fed while 35 received solid foods or infant formula in addition to breast milk.

Infants were allowed to suckle for a few minutes before a breast milk sample was collected by manual expression, and thereafter feeding was continued. The samples were stored at $-70^{\circ} \mathrm{C}$ until analysis.

An informed consent was asked from all the mothers participating in the study, and the study was approved by the First Ethical Committee of the Hospital District of South-West Finland and the Ethical Committee of Tampere University Hospital.

Analysis of cytokine concentrations in breast milk. The breast milk samples were thawed, mixed by vortex, and subsequently centrifuged at $8832 \times g$ for $5 \mathrm{~min}$ at room temperature to separate fat and cells from whey. The concentrations of TNF- $\alpha$, IL-4, IL-10, and TGF- $\beta_{2}$ in whey were determined using commercial sandwich ELISAs specific to these molecules (R\&D Systems Europe Ltd, Abindgon, U.K.). Assays were performed as recommended by the manufacturer, except that latent TGF- $\beta_{2}$ was activated as previously described (14). Briefly, the milk was incubated at room temperature for $1 \mathrm{~h}$ with $1 \mathrm{M}$ acetic acid and neutralized with $1.2 \mathrm{M} \mathrm{NaOH} / 0.5 \mathrm{M}$ HEPES. All assays were performed in duplicate.

Analysis of eicosanoid concentrations in breast milk. $\mathrm{PGE}_{2}$ was measured by RIA using reagents supplied by Amersham Pharmacia Biotech (Biotrak RPA 530; Buckinghamshire, U.K.). The amount of Cys-LTs was measured by ELISA using reagents supplied by Amersham Pharmacia Biotech (Biotrak RPN 224).

Analysis of fatty acid composition of the breast milk. The breast milk samples were thermostated at $40^{\circ} \mathrm{C}$ for an hour and thoroughly mixed before aliquots of $0.5 \mathrm{~g}$ were taken for fatty acid analysis. Methyl nonadecanoate $(5.0 \mathrm{mg}$; $99+\%$; NuCheck Prep. Inc., Elysian, MN U.S.A.) in ethanol was added as the internal standard, and the ethanolic solution was alkalinized with ammonium. Lipids were extracted three times with petroleum and diethyl ethers according to the FIL-IDF standard (15). Fatty acids were methylated with boron trifluoride (16) before analysis by capillary gas chromatography. Fatty acid methyl esters were injected using on-column technique to a NB-351 column $(25 \mathrm{~m} \times 0.32 \mathrm{~mm} \times 0.2 \mu \mathrm{m}$; HNU Nordion, Helsinki, Finland). The gas chromatography conditions were as follows: injector and oven temperatures were programmed from $60^{\circ} \mathrm{C}$ to $240^{\circ} \mathrm{C}$; flame ionization detector temperature was $260^{\circ} \mathrm{C}$, and helium was used as the carrier gas with a constant flow rate of $2.0 \mathrm{~mL} / \mathrm{min}$. Fatty acid methyl esters were assumed to give equal responses in the detector. Fatty acid contents were calculated from the respective methyl esters and triacylglycerol contents by multiplying the total fatty acid contents by 1.046 (17). Each breast milk sample was analyzed for fatty acids in duplicate.

Statistical analysis. Differences between two unpaired groups were evaluated by the independent samples $t$ test or by differences between the means and their confidence intervals (18) for normally distributed variables and by the Mann-Whitney $U$ test for variables not normally distributed. Correlations between two variables were calculated by the Spearman rank correlation coefficient. Values are reported as mean and SD or as median and range or interquartile range, unless otherwise specified. A $p$ value of $<0.05$ was considered statistically significant. All statistical analyses were performed on SPSS for Windows (version 10.0.5; SPSS Inc., Chicago, IL, U.S.A.).

\section{RESULTS}

The clinical characteristics of the mothers and their infants are summarized in Table 1. The two groups were comparable except for the presence or absence of AD. The most common $\mathrm{AD}$ in the mothers was allergic rhinitis, followed by food allergy and atopic eczema.

The prevalence and concentrations of the analyzed cytokines and eicosanoids in breast milk are presented in Table 2 .

Table 1. Clinical characteristics of mothers with and without $A D$ and of their infants

\begin{tabular}{|c|c|c|}
\hline & $\begin{array}{c}\text { Mothers with } \mathrm{AD} \\
\quad(n=43)\end{array}$ & $\begin{array}{c}\text { Mothers without } \mathrm{AD} \\
\quad(n=51)\end{array}$ \\
\hline \multicolumn{3}{|l|}{ Mothers } \\
\hline \multicolumn{3}{|l|}{ Type of AD* } \\
\hline Atopic eczema & $13(24) \dagger$ & \\
\hline Asthma & $3(6)$ & \\
\hline Allergic rhinitis & $24(44)$ & \\
\hline Food allergy & $14(26)$ & \\
\hline $\begin{array}{l}\text { Duration of gestation } \\
\text { (weeks) }\end{array}$ & $40(36-42) \div$ & $40(37-42)$ \\
\hline \multicolumn{3}{|l|}{ Mode of delivery§ } \\
\hline Vaginal & $38(88) \dagger$ & $44(92)$ \\
\hline Cesarean & $5(12)$ & $4(8)$ \\
\hline \multicolumn{3}{|l|}{ Children } \\
\hline Birth weight (g) & $3634(2750-4950) \ddagger$ & $3644(2950-4590)$ \\
\hline Birth length $(\mathrm{cm})$ & $50(47-53) \ddagger$ & $51(47-54)$ \\
\hline $\begin{array}{l}\text { Head circumference at } \\
\text { birth }(\mathrm{cm}) \S\end{array}$ & $35(33-38) \div$ & $35(33-37)$ \\
\hline \multicolumn{3}{|l|}{ Siblings } \\
\hline 0 & $37(86) \dagger$ & $33(66)$ \\
\hline 1 or more & $6(14)$ & $17(34)$ \\
\hline
\end{tabular}

* 11 mothers were classified into more than one category of AD.

$\dagger n(\%)$.

$\$$ Mean (range).

$\S$ Data on 1-3 subjects missing because of delivery in another hospital. 
Table 2. Prevalence and concentrations of cytokines and eicosanoids in breast milk of mothers with and without AD

\begin{tabular}{|c|c|c|c|c|c|c|c|}
\hline Cytokine & Detection limit & \multicolumn{3}{|c|}{ Mothers with AD } & \multicolumn{3}{|c|}{ Mothers without AD } \\
\hline TNF- $\alpha$ & $4.4 \mathrm{ng} / \mathrm{L}$ & 4/31 (13) & $<4.4$ & $<4.4-21.3$ & 7/38 (18) & $<4.4$ & $<4.4-15.1$ \\
\hline IL-10 & $3.9 \mathrm{ng} / \mathrm{L}$ & $3 / 38(8)$ & $<3.9$ & $<3.9-10.8$ & 4/40 (10) & $<3.9$ & $<3.9-49.4$ \\
\hline TGF- $\beta_{2}$ & $7.0 \mathrm{ng} / \mathrm{L}$ & $37 / 37(100)$ & $420 \dagger$ & $153-42,117$ & $38 / 38(100)$ & 539 & $255-21,094$ \\
\hline $\mathrm{PGE}_{2}$ & $6.3 \mathrm{ng} / \mathrm{L}$ & $36 / 36(100)$ & 184 & $58-829$ & $46 / 46(100)$ & 175 & 39-902 \\
\hline
\end{tabular}

* Number of samples above detection limit in relation to total number of measurements (\%).

$\dagger$ Different from mothers without $\mathrm{AD} ; p=0.031$ (Mann-Whitney $U$ test).

TGF- $\beta_{2}$ of cytokines and $\mathrm{PGE}_{2}$ and Cys-LTs of eicosanoids were detected in all breast milk samples, whereas cytokines TNF- $\alpha$ and IL- 10 were detected in $16 \%$ and $9 \%$ of the samples, respectively. None of the samples reached the detection limit for IL-4. The concentration of TGF- $\beta_{2}$ was lower in mothers with AD compared with mothers without ( $p=0.003$; Fig. 1), whereas concentrations of the other cytokines and eicosanoids were similar in the two groups.

The total amounts of triacylglycerols in the breast milk were not significantly different in mothers with $\mathrm{AD}$ compared with mothers without (mean \pm SD: $40 \pm 21 \mathrm{~g} / \mathrm{L}, n=28$ and $37 \pm$ $18 \mathrm{~g} / \mathrm{L}, n=39$, respectively; NS). The fatty acids docosa-

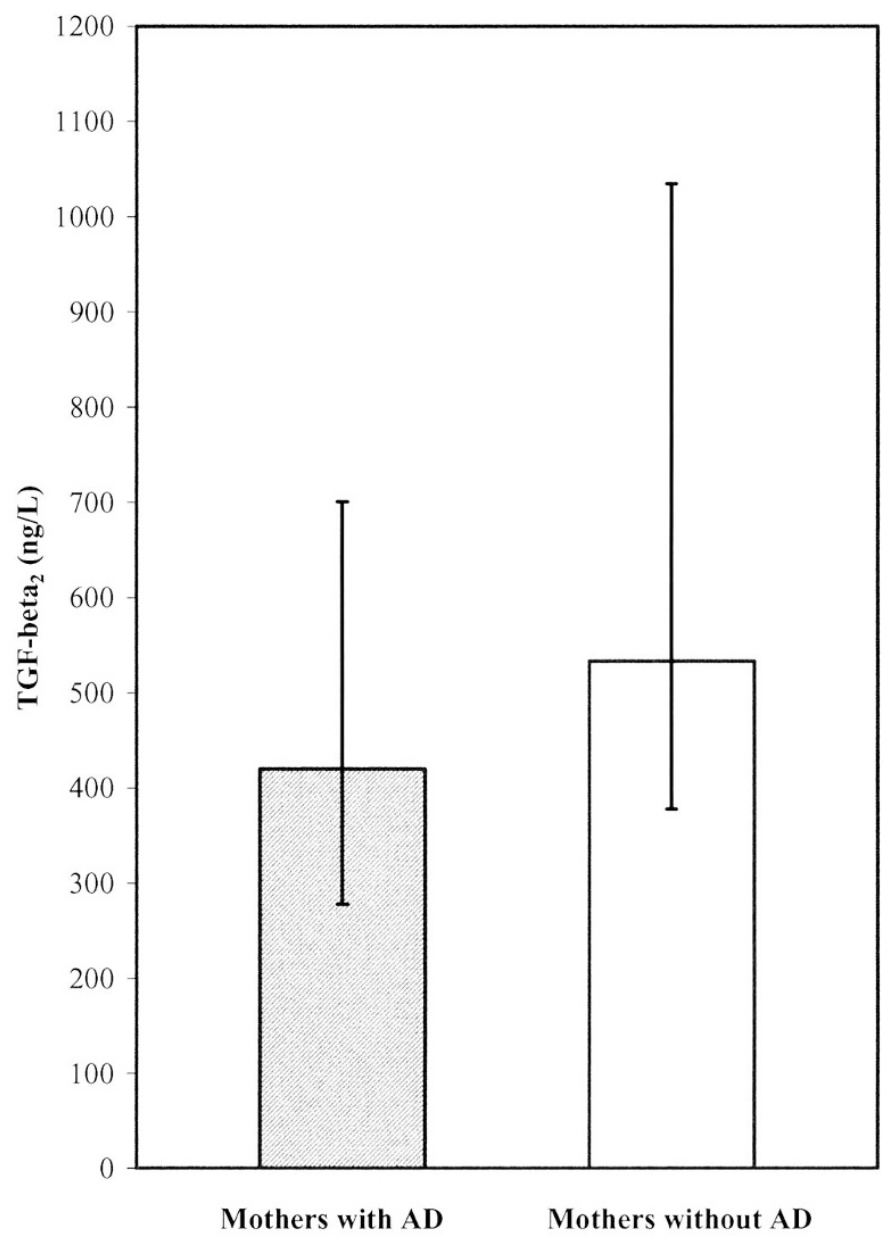

Figure 1. Concentrations of TGF- $\beta_{2}$ in breast milk in mothers with $\mathrm{AD}(n=$ $37)$ and without $\mathrm{AD}(n=38)$. Median and interquartile range; $p=0.0031$.

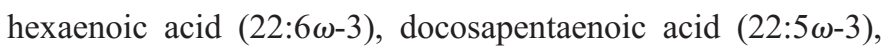
and $\gamma$-linoleic acid $(18: 3 \omega-6)$ could not be detected or were insufficiently separated $(22: 6 \omega-3)$ in the samples in the gas chromatographic conditions used in the study. The proportions of other individual fatty acids or fatty acid groups were not different between the two groups (Table 3).

The breast milk inflammatory factors and fatty acid composition were shown to be related. A positive association was observed between TGF- $\beta_{2}$ and proportions of PUFA ( $\sigma=$ $0.29, p=0.038, n=53)$ and $\omega-6$ fatty acids $(\sigma=0.34, p=$ $0.012, n=53)$ in total fatty acid content and a negative association between TGF- $\beta_{2}$ and proportion of SFA $(\sigma=$ $-0.30, p=0.029, n=53$ ) in total fatty acids (Fig. 2). TGF- $\beta_{2}$ was not associated with the proportion of $\omega-3$ fatty acids. $\mathrm{PGE}_{2}$ was related with Cys-LTs $(\sigma=0.34, p=0.002, n=82)$ and

Table 3. Prevalence of the major fatty acids (\% of total fatty acids) in breast milk of mothers with and without AD

\begin{tabular}{|c|c|c|c|}
\hline Fatty acid & $\begin{array}{c}\text { Mothers } \\
\text { with AD } \\
(n=28)^{*}\end{array}$ & $\begin{array}{c}\text { Mothers } \\
\text { without AD } \\
(n=40)^{*}\end{array}$ & Difference $\dagger$ \\
\hline \multicolumn{4}{|l|}{ Saturated } \\
\hline 10:0 & $1.41 \pm 0.44$ & $1.45 \pm 0.55$ & $-0.04(-0.29,0.21)$ \\
\hline $12: 0$ & $5.63 \pm 1.83$ & $6.06 \pm 2.44$ & $-0.43(-1.52,0.65)$ \\
\hline $14: 0$ & $6.34 \pm 1.77$ & $6.88 \pm 2.25$ & $-0.54(-1.56,0.48)$ \\
\hline $16: 0$ & $22.62 \pm 2.30$ & $21.73 \pm 5.55$ & $0.89(-1.33,3.11)$ \\
\hline $18: 0$ & $8.54 \pm 1.94$ & $7.93 \pm 1.75$ & $0.61(1.51,1.53)$ \\
\hline \multicolumn{4}{|l|}{ Monounsaturated } \\
\hline $16: 1 \omega-9$ & $0.33 \pm 0.09$ & $0.36 \pm 0.11$ & $-0.03(-0.08,0.03)$ \\
\hline $16: 1 \omega-7$ & $2.46 \pm 0.74$ & $2.79 \pm 0.95$ & $-0.33(-0.76,0.10)$ \\
\hline $18: 1 \omega-9$ & $35.37 \pm 3.15$ & $35.50 \pm 4.39$ & $-0.12(-2.05,1.82)$ \\
\hline $18: 1 \omega-7$ & $2.90 \pm 1.06$ & $3.18 \pm 1.21$ & $-0.27(-0.84,0.29)$ \\
\hline \multicolumn{4}{|l|}{ Polyunsaturated } \\
\hline $18: 2 \omega-6$ & $9.31 \pm 2.00$ & $9.17 \pm 1.71$ & $0.14(-0.76,1.04)$ \\
\hline $20: 3 \omega-6$ & $0.28 \pm 0.08$ & $0.28 \pm 0.09$ & $0.003(-0.04,0.05)$ \\
\hline $20: 4 \omega-6$ & $0.31 \pm 0.09$ & $0.34 \pm 0.12$ & $-0.03(-0.08,0.03)$ \\
\hline $18: 3 \omega-3$ & $2.04 \pm 0.71$ & $1.95 \pm 0.64$ & $0.09(-0.24,0.42)$ \\
\hline $20: 5 \omega-3$ & $0.10 \pm 0.06$ & $0.09 \pm 0.06$ & $0.007(-0.02,0.04)$ \\
\hline \multicolumn{4}{|l|}{ Total } \\
\hline SFA & $45.31 \pm 5.22$ & $44.83 \pm 7.12$ & $0.48(-2.67,3.64)$ \\
\hline MUFA & $42.13 \pm 3.69$ & $42.85 \pm 5.35$ & $-0.72(-3.06,1.61)$ \\
\hline PUFA & $12.24 \pm 2.54$ & $12.01 \pm 2.29$ & $0.23(-0.95,1.41)$ \\
\hline$\omega-6$ & $10.10 \pm 2.07$ & $9.96 \pm 1.84$ & $0.14(-0.81,1.09)$ \\
\hline$\omega-3$ & $2.14 \pm 0.71$ & $2.05 \pm 0.66$ & $0.09(-0.24,0.43)$ \\
\hline \multicolumn{4}{|l|}{ Ratios } \\
\hline $18: 2 \omega-6 / 18: 3 \omega-3$ & $4.88 \pm 1.24$ & $5.16 \pm 1.83$ & $-0.28(-1.08,0.51)$ \\
\hline$\omega-6 / \omega-3$ & $5.02 \pm 1.24$ & $5.37 \pm 2.05$ & $-0.35(-0.52,0.45)$ \\
\hline
\end{tabular}

$*$ Mean $\pm \mathrm{SD}$

$\dagger$ Mean ( $95 \%$ confidence intervals).

MUFA, monounsaturated fatty acids. 


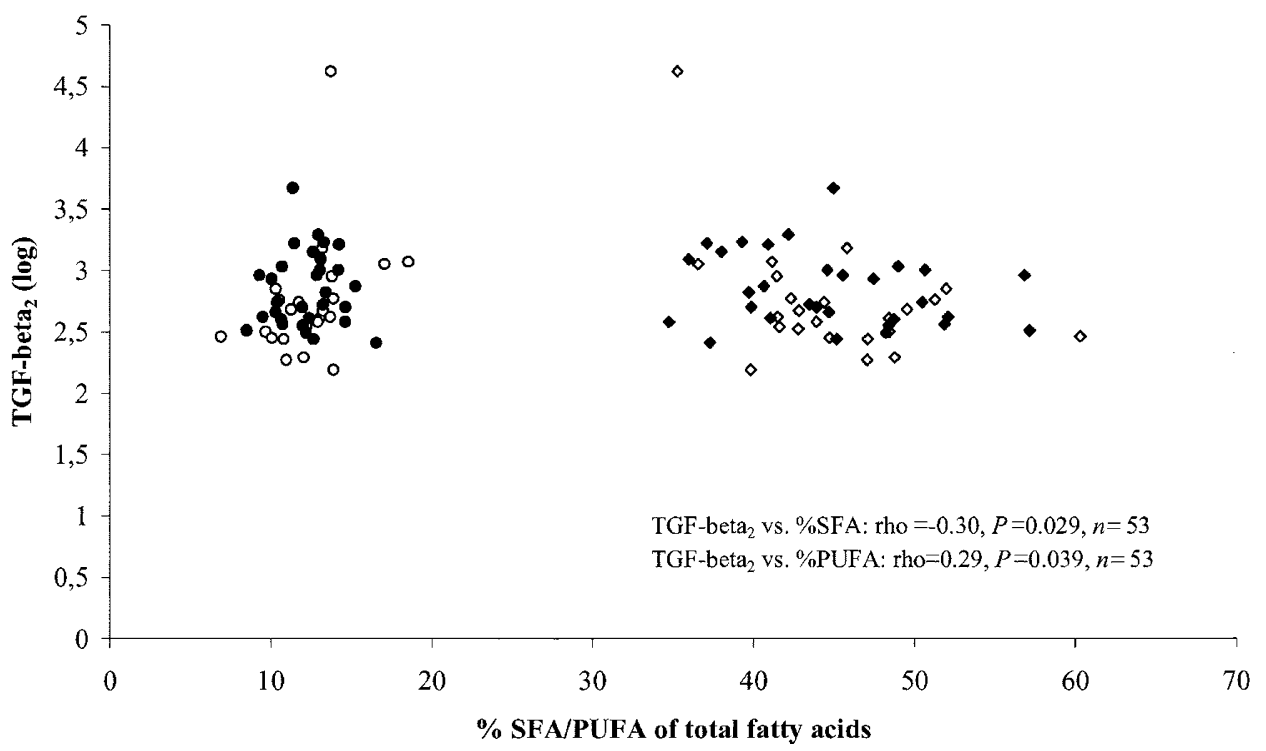

Figure 2. Relations between concentration of TGF- $\beta_{2}$ and proportion of SFA $(\diamond, \diamond)$ and PUFA $(\odot, \bullet)$ among total fatty acids in breast milk. Mothers with $\mathrm{AD}$ are indicated by open symbols and mothers without by solid symbols.

with the proportion of dihomo- $\gamma$-linolenic acid $(20: 3 \omega-6 ; \sigma=$ $0.26, p=0.036, n=64$ ) in the total fatty acids. Breast milk Cys-LTs were associated with the proportions of dihomo- $\gamma$ linolenic acid $(20: 3 \omega-6 ; \sigma=0.32, p=0.011, n=64)$ and eicosapentaenoic acid $(20: 5 \omega-3 ; \sigma=0.41, p=0.001, n=64)$ in total fatty acids. However, neither $\operatorname{PGE}_{2}(\sigma=0.23, p=$ $0.067, n=64)$ nor Cys-LTs $(\sigma=0.19, p=0.125, n=64)$ were associated with the proportion of arachidonic acid $(20: 4 \omega-6)$ of total fatty acids.

\section{DISCUSSION}

The immunologic hallmark of $\mathrm{AD}$ is an imbalance between regulatory cytokines produced by distinct $\mathrm{TH}$ cell subtypes. Interestingly, this study revealed that in addition to cytokines, other mediators may also regulate the delicate immunologic balance. The possibility that aberrant properties of breast milk may be transferred from mother to child and the composition of breast milk be influenced presents a particular challenge in the fight against $\mathrm{AD}$.

Several studies have indicated that maternal atopy and AD, even more profoundly than paternal $\mathrm{AD}$, increases the risk of atopy and $\mathrm{AD}$ in the infant (5-8). In a recent study, in comparison to paternal atopy, maternal atopy involved a more than 3-fold risk of atopy in child (8). Although some of the transmission of AD may be inherited, the differential impact of the maternal and the paternal $\mathrm{AD}$ on the risk of disease in the infant implies that the relationship between the mother and the fetus or infant is a stronger determinant of the immune responder type of the child, possibly enduringly. The relations between immunologic factors, including cytokines, fatty acids, and eicosanoids, in breast milk may influence the delicate balance of the gut immune milieu of the infant and thus may have health effects on the breast-fed infant. Indeed, a major mechanism whereby a healthy immune homeostasis is maintained takes place via control of cytokines produced by TH1, $\mathrm{TH} 2$, and Tr-like cells (19). In the context of AD, harmful properties have been extensively described for IL-4, TNF- $\alpha$, and interferon- $\gamma$, whereas antiinflammatory or protective properties, mainly via induction of oral tolerance, have been described for TGF- $\beta_{2}$ and IL-10 (20). Particularly breast milk TGF- $\beta_{2}$ may play a key role with respect to the prevention of $\mathrm{AD}(21)$.

In the present study we demonstrate a lower concentration of TGF- $\beta_{2}$ in breast milk in mothers with $\mathrm{AD}$ compared with those without. Furthermore, our results imply that regulatory circuits of fatty acid, eicosanoid, and cytokine metabolism may be connected. The associations observed suggest that the immunomodulatory properties of breast milk may not be envisaged in terms of single factors; a joint action may be required.

Our results on the prevalence and concentrations of cytokines in the breast milk in healthy mothers are similar to those reported elsewhere, showing that TGF- $\beta_{2}$ has frequently been measured in breast milk (21-25). Moreover, in accord with previous data, cytokines IL-4, IL-10, and TNF- $\alpha$ were not detected or were only detected in low concentrations $(23,24$, 26). Whereas Böttcher and coworkers (25) found a higher concentration of IL-4 in the colostrum of mothers with AD compared with mothers without $\mathrm{AD}$, we were not able to demonstrate such a difference in the breast milk given to older infants. A key difference between the present study and that of Böttcher and coworkers (25) is that they described AD as symptoms and a positive IgE response to inhalant allergens, i.e. expression of atopy and $\mathrm{AD}$ together. Because $\mathrm{IgE}$ is under regulation by IL-4, their cohort may have been focused on a more extreme population as reflected also in breast milk composition.

Compared to cytokines, PUFAs are considered to have both proinflammatory and antiinflammatory properties. Generally $\omega-6$ PUFAs, as well as eicosanoids derived from them, are considered proinflammatory, whereas $\omega-3$ PUFAs are considered antiinflammatory (11). However, evidence is accumulating to suggest that $\omega-6$ fatty acids may actually be antiinflam- 
matory via the effects of TH3 or Tr cells and thus via TGF- $\beta_{2}$ and IL-10 production. In the present study the breast milk samples were collected in a systematic way, and the results are presented as a proportional fatty acid composition rather than concentrations to reduce the variability in the fatty acid composition caused by factors other than biologic variability. Our results would imply than in addition to $\omega-6$ fatty acids, the proportion of total PUFA, and more surprisingly total SFA, may be an important regulator of the immune milieu of breast milk. Nonetheless, no difference was found in the proportional fatty acid composition or in the concentrations of $\mathrm{PGE}_{2}$ and Cys-LTs in the breast milk of mothers with and without AD. Our results for fatty acid composition are similar to those obtained by Schroten and associates (27). Decreased levels, particularly of $\mathrm{PGE}_{2}$ precursor fatty acids in the breast milk of mothers with $\mathrm{AD}$, have previously been observed (28-30). Eicosanoids, particularly $\mathrm{PGE}_{2}$, have been measured in breast milk $(24,31-33)$, but no comparisons between allergic and healthy mothers have been undertaken. Consequently, an altered fatty acid composition in breast milk in mothers with $\mathrm{AD}$ has hitherto commonly been explained by an impaired capacity to metabolize PUFA, and it has been estimated that this would result in altered eicosanoid production $(28,29,34,35)$.

An alternative explanation for a defect in PUFA metabolism in $\mathrm{AD}$ may be put forward. The development of AD may rather be caused by the immune responses resulting from metabolic events occurring after the synthesis of eicosanoids. In studies by Rocklin and coworkers $(36,37)$ it was shown in vitro that the sensitivity and the amount of $\mathrm{PGE}_{2}$ receptors in the effector $\mathrm{T}$ cells is reduced in $\mathrm{AD}$. This would result in a deficient $\mathrm{PGE}_{2}$ feedback inhibition and would prevent the differentiation and proliferation of $\mathrm{TH}$ precursor cells to $\mathrm{Tr}$ and $\mathrm{TH} 3$ cells and thus the production of TGF- $\beta_{2}$. In the same way, the role of $\mathrm{PGE}_{2}$ as a modulator of immune function was shown in a recent experimental animal study in which antigen stimulation upregulated $\mathrm{PGE}_{2}$ production from arachidonic acid and consequently suppressed antigen-specific T-cell proliferation in gutassociated lymphoid tissue, thus contributing to an antiinflammatory intestinal environment (38). These events might also explain the reduced TGF- $\beta_{2}$ concentration in the breast milk of mothers with $\mathrm{AD}$ observed in this study.

\section{CONCLUSIONS}

The breast milk cytokines, eicosanoids, and fatty acids were shown to be related. In view of the several beneficial effects of TGF- $\beta_{2}$ on the development of the mucosal immune system of the breast-fed infant, a low TGF- $\beta_{2}$ concentration observed in this study may represent a health risk for the infant. The observed associations between the nutritional and inflammatory factors in breast milk suggest that it may be possible to influence the immune milieu of the gut depending on the breast milk composition. By modifying the breast milk fatty acid composition in a specific manner it may be possible to enforce those properties of the milk that are immune-protective for the infant. Failure to achieve this in a preliminary attempt (39) calls for experimental studies with precise documentation of the intervention and evaluation of the background diet, espe- cially because diet is always a combination of many foods and nutrients, and their interactions and effects on immune function may outweigh the significance of using single-nutrient supplements.

Acknowledgments. The authors thank Satu Sivula and Laura Holkeri for technical assistance, Ulla-Maija Eriksson and Elisa Hovimäki for contribution to contacts with the study subjects, Tuija Poussa for statistical assistance, and Robert MacGilleon for revision of the English text.

\section{REFERENCES}

1. Gdalevich M, Mimouni D, David M, Mimouni M 2001 Breast-feeding and the onset of atopic dermatitis in childhood: a systematic review and meta-analysis of prospective studies. J Am Acad Dermatol 45:520-257

2. Mimouni Bloch A, Mimouni D, Mimouni M, Gdalevich M 2002 Does breastfeeding protect against allergic rhinitis during childhood? A meta-analysis of prospective studies. Acta Paediatr 91:275-279

3. Gdalevich M, Mimouni D, Mimouni M 2001 Breast-feeding and the risk of bronchial asthma in childhood. A systematic review with meta-analysis of prospective studies. J Pediatr 139:261-266

4. Halken S, Host A 2001 Prevention. Curr Opin Allergy Clin Immunol 1:229-236

5. Ruiz RGG, Kemeny DM, Price JF 1992 Higher risk of infantile atopic dermatitis from maternal atopy than from paternal atopy. Clin Exp Allergy 22:762-766

6. Sears MR, Holdaway MD, Flannery EM, Herbison GP, Silva PA 1996 Parental and neonatal risk factors for atopy, airway hyper-responsiveness, and asthma. Arch Dis Child 75:392-398

7. Sarafino EP 2000 Connections among parent and child atopic illnesses. Pediatr Allergy Immunol 11:80-86

8. Illi S, von Mutius E, Lau S, Nickel R, Niggemann B, Sommerfeld C, Wahn U, the Multicenter Allergy Study Group 2001 The pattern of atopic sensitization is associated with the development of asthma in childhood. J Allergy Clin Immunol 108:709714

9. Prescott SL, Macaubas C, Smallcombe T, Holt BJ, Sly PD, Holt PG 1999 Development of allergen-specific T-cell memory in atopic and normal children. Lancet 353:196-200

10. Kulig M, Tacke U, Forster J 1999 Serum IgE levels during the first 6 years of life. J Pediatr 134:453-458

11. Calder PC 1998 Fat chance of immunomodulation. Immunol Today 19:244-247

12. Romagnani S 2000 T-cell subsets (Th1 versus Th2). Ann Allergy Asthma Immunol $85: 9-21$

13. James MJ, Gibson RA, Cleland LG 2000 Dietary polyunsaturated fatty acids and inflammatory mediator production. Am J Clin Nutr 71(suppl):343-348

14. Pakkanen R 1998 Determination of transforming growth factor- $\beta 2$ (TGF- $\beta 2$ ) in bovine colostrum samples. J Immunoassay 19:23-37

15. FIL-IDF Standard 1C 1987 Milk: determination of fat content-Röse Gottlieb gravimetric method (Reference Method). International Dairy Federation, Brussels, Belgium, $8 \mathrm{P}$

16. Slover L, Lanza E 1979 Quantitative analysis of food fatty acids by capillary gas chromatography. J Am Oil Chem Soc 56:933-943

17. Hyvönen L, Lampi A-M, Varo P, Koivistoinen P 1993 Fatty acid analysis, TAG equivalents as net fat value, and nutritional attributes of commercial fats and oils. J Food Compos Anal 6:24-40

18. Gardner MJ, Altman DG 1986 Confidence intervals rather than $p$ values: estimation rather than hypothesis testing. BMJ 292:746-750

19. Spiekermann GM, Walker WA 2001 Oral tolerance and its role in clinical disease. J Pediatr Gastroenterol Nutr 32:237-255

20. Weiner HL 2001 Oral tolerance immune mechanisms and the generation of Th3-type TGF- $\beta$-secreting regulatory cells. Microbes Infect 3:947-954

21. Kalliomäki M, Ouwehand A, Arvilommi H, Kero P, Isolauri E 1999 Transforming growth factor- $\beta$ in breast milk: a potential regulator of atopic disease at an early age. J Allergy Clin Immunol 104:1251-1257

22. Saito S, Yoshida M, Ichijo M, Ishizaka S, Tsujii T 1993 Transforming growth factor- $\beta$ (TGF- $\beta$ ) in human milk. Clin Exp Immunol 94:220-224

23. Srivastava MD, Srivastava A, Brouhard B, Saneto R, Groh-Wargo S, Kubit J 1996 Cytokines in human milk. Res Commun Mol Pathol Pharmacol 93:263-287

24. Hawkes JS, Bryan D-L, James MJ, Gibson RA 1999 Cytokines (IL-1 $\beta$, IL-6, TNF- $\alpha$, TGF- $\beta 1$, and TGF- $\beta 2$ ) and prostaglandin $E_{2}$ in human milk during the first three months postpartum. Pediatr Res 46:194-199

25. Böttcher MF, Jenmalm MC, Garofalo RP, Björksten B 2000 Cytokines in breast milk from allergic and nonallergic mothers. Pediatr Res 47:157-162

26. Garofalo R, Chheda S, Mei F, Palkowetz KH, Rudloff HE, Schmalstieg FS, Rassin DK, Goldman AS 1995 Interleukin-10 in human milk. Pediatr Res 37:444-449

27. Schroten H, Schöls K, Melnik B, Kries R, Wahn V, Biggemann B 1992 Breast milk of atopic mothers provides their infants with normal amounts of $\omega$-6-fatty acids. Pediatr Allergy Immunol 3:140-143

28. Yu G, Duchén K, Björkstén B 1998 Fatty acid composition in colostrum and mature milk from non-atopic and atopic mothers during the first 6 months of lactation. Acta Paediatr 87:729-736 
29. Thijs C, van Houwelingen A, Poorterman I, Mordant A, van den Brandt P 2000 Essential fatty acids in breast milk of atopic mothers: comparison with non-atopic mothers, and effect of borage oil supplementation. Eur J Clin Nutr 54:234-238

30. Kankaanpää P, Nurmela K, Erkkilä A, Kalliomäki M, Holmberg-Marttila D, Salminen S 2001 Polyunsaturated fatty acids in maternal diet, breast milk and serum lipid fatty acids of infants in relation to atopy. Allergy 56:633-638

31. Lucas A, Mitchell MD 1980 Prostaglandins in human milk. Arch Dis Child 55:950-952

32. Reid B, Smith H, Friedman Z 1980 Prostaglandins in human milk. Pediatrics $66: 870-872$

33. Neu J, Wu-Wang C-Y, Measel CP, Gimotty P 1988 Prostaglandin concentrations in human milk. Am J Clin Nutr 47:649-652

34. Businco L, Ioppi M, Morse NL, Nisini R, Wright S 1993 Breast milk from mothers of children with newly developed atopic eczema has low levels of long chain polyunsaturated fatty acids. J Allergy Immunol 91:1134-1139
35. Duchén K, Yu G, Björkstén B 1998 Atopic sensitization during the first year of life in relation to long chain polyunsaturated fatty acid levels in human milk. Pediatr Res 44:478-484

36. Rocklin RE, Thistle L, Audera C 1985 Decreased sensitivity of atopic mononuclear cells to prostaglandin $\mathrm{E}_{2}\left(\mathrm{PGE}_{2}\right)$ and prostaglandin $\mathrm{D}_{2}\left(\mathrm{PGD}_{2}\right)$. J Immunol 135:20332039

37. Rocklin RE, Thistle L 1986 Reduced prostaglandin $\mathrm{E}_{2}\left(\mathrm{PGE}_{2}\right)$ receptors on atopic $\mathrm{T}$ lymphocytes. Cell Immunol 99:294-299

38. Newberry RD, Stenson WF, Lorenz RG 1999 Cyclooxygenase-2-dependent arachidonic acid metabolites are essential modulators of the intestinal immune response to dietary antigen. Nat Med 5:900-906

39. Hawkes JS, Bryan D-L, Neumann MA, Makrides M, Gibson RA 2001 Transforming growth factor beta in human milk does not change in response to modest intakes of docosahexaenoic acid. Lipids 36:1179-1181 